\title{
THE ERUPTION SEQUENCE OF PRIMARY AND PERMANENT TEETH IN A GROUP OF CHILDREN (A CROSS-SECTIONAL STUDY)
}

\author{
Moataz Elkhatib*, Norhan El- Dokky** and Rania Nasr ${ }^{* * *}$
}

\begin{abstract}
Aim: Determine eruption dates \& sequence and to correlate between chronological and developmental age of eruption of primary and permanent teeth.

Methods: Study sample consisted of 1526 apparently healthy children of both genders, 1020 children were selected from schools, and 506 children were selected from children attending Maternal and Child Welfare Centers.

Results: Eruption sequence in primary teeth in both genders was: lower primary central incisor (LA), Upper primary central incisor (UA), upper primary lateral incisor (UB), lower primary lateral incisor (LB), upper primary first molar (UD), lower primary first molar (LD), Upper primary canine (UC), lower primary canine (LC), lower primary second molar (LE), and upper primary second molar (UE). Sequence of eruption of permanent teeth in boys was: lower permanent first molar (L6), lower permanent central incisor (L1), lower permanent lateral incisor (L2), upper permanent central incisor (U1), upper permanent lateral incisor (U2), upper permanent first molar (U6), lower permanent first premolar (L4), upper permanent first premolar (U4), upper permanent second premolar (U5), lower permanent canine (L3), lower permanent second premolar (L5), lower permanent second molar (L7), upper permanent second molar (U7) and upper permanent canine (U3). In girls: L1, L2, U1, U2, U6, L6, L3, L4, L5, U4, U5, L7, U7, and U3. In boys, deviation from the standard range exceeding 50\% except for LA, UE, and LE. In girls, deviation was exceeding $50 \%$ in UC, UE, LA, LB, LC, LD, and LE. There were statistically significant difference between means age of eruption of permanent teeth in boys and girls for U1, U2, U5, U6, and L6.
\end{abstract}

Conclusion: Sequence and dates of eruption of teeth differ among populations. Orthodontists and pediatric dentists can rely on specific standards of Eruption dates \& sequence for diagnosis, treatment planning, and preventive programs.

KEYWORDS: Eruption sequence, Chronology of tooth eruption, Permanent teeth and Deciduous teeth.

\footnotetext{
* Researcher at Orthodontic Department, Faculty of Dentistry, Cairo University.

** Professor, Pediatric Dentistry and Public Health Department, Faculty of Dentistry, Cairo University.

*** Associate Professor, Pediatric Dentistry and Dental Public Health Department, Cairo University, and Modern University of Technology and Informations.
} 


\section{INTRODUCTION}

Eruption is described as a development process that moves a tooth from its crypt to its last position in occlusion with its antagonist through the alveolar bone ${ }^{(1)}$. This process involves the completion of root development, periodontium formation and preservation of functional occlusion, whilst, on the other hand, emergence can be used to describe the appearance of any portion of the cusp via the gingiva. Emergence is correlated with the eruption moment, continuously it founded as an eruptive scientific indicator ${ }^{(2)}$. Tooth eruption is an active biological mechanism through which the teeth in the oral cavity appears ${ }^{(3)}$.

While passive eruption is characterized as the apical migration of the gingival tissue to or near the cement-enamel junction, which specifies the location of the gingival margin. Both processes simultaneously continue after the disruption of the oral epithelium ${ }^{(4)}$.

Eruption is subject to a wide variety of individuals, particularly in permanent teeth. A group of physiological factors (i.e. inheritance, constitution, geographical factors, gender, nutrition, climate, race or urbanization), pathological and systemic factors (several diseases, e.g. endocrine diseases, brain paralysis, severe intoxication, genetic diseases, and severe renal diseases), local pathological factors (e.g. local obstacles, space deficiency, and hypodontia) ${ }^{(5)}$.

When a tooth appeared in the oral cavity well after the established standards, a tooth eruption is considered delayed. Delayed permanent tooth eruption is one of the most severe issues during the mixed stage. Delayed permanent teeth may affect the exact diagnosis and treatment planning of the orthodontic process and can extend the treatment overall required ${ }^{(1)}$.

General, systemic and local causes can be responsible for delayed tooth eruption. General causes such as gender, premature birth, Body Mass Index, growth factors, differences in race and population, and socioeconomic factors ${ }^{(6,7)}$. Local factors such as gingival hyperplasia, supernumerary teeth, odontomas, tooth retention, arch-length deficiencies ${ }^{(2,8)}$. Systemic causes include genetic disease, malnutrition, and hormonal disturbance ${ }^{(9,10)}$.

\section{Difference in Timing and Sequence of Eruption:}

Persons from various ethnic and racial groups showed various patterns of eruption and different times. Such differences had to be examined and the basis for creating a modern standard table for tooth eruption timings specific to the community used ${ }^{(11)}$.

\section{Primary}

A cross-section analysis of 541 children (3-36) months of age found that boys surpassed girls primary teeth in $\mathrm{LB}, \mathrm{UC}, \mathrm{LC}, \mathrm{UE}$, and $\mathrm{LE}^{(12)}$.

Another study in which the sample consisted of 2212 children aged (3-36) months from Qalyubia governorate was conducted. The first tooth to erupt was the LA with a mean age of 7.62 months in boys and 7.2 months in girls. Eruption sequence among boys LA, UA, UB, LB, LD, UC, UD, LC, UE, and LE, and among girls LA, UA, UB, LB, LD, UD, $\mathrm{UC}, \mathrm{LC}, \mathrm{LE}$, and UE ${ }^{(13)}$.

In addition, 536 children (3-36) months of age randomly were chosen from Giza governorate and analyzed through observational study. It had not been observed that the mean age of eruption of upper primary teeth are statistically significantly different in boys and girls and a large ratio of divergence from the standard range ${ }^{(14)}$ was higher than $50 \%$ in $\mathrm{UB}, \mathrm{UC}, \mathrm{LA}, \mathrm{LB}$ and $\mathrm{LC}^{(15)}$.

\section{Permanent}

A cross-section analysis was performed in a sample of 2,000 children of both genders (5-13) years of age and found that the first tooth to emerge was L1 at 6.25 and 6.38 years of age, in males and 
females respectively. The pattern of eruptions was distinct among males and females ${ }^{(16)}$.

Another cross-section study of 1,031 children aged 5-12 years from Kafr-Elsheikh governorate showed that the first tooth erupted was the L6 in both boys and girls. Girls preceded boys in permanent teeth eruption in certain teeth; U2, L2, L3, L4, U6, and L7 (12).

Finally, a cross-section analysis was performed on a group of 2212 children. There was a statistically significant difference between the mean ages of permanent teeth eruption for boys and girls except for U3, L4, and L7, with negligible variations between the two groups ${ }^{(13)}$.

Therefore, based on the available data, which revealed variations in the timing of eruptions in both primary and permanent teeth, the present study was conducted to determine the date (average time) and sequence of eruption of primary and permanent teeth and to correlate between the chronological and developmental ages of eruption of primary and permanent teeth in a group of children.

\section{SUBJECTS AND METHODS}

The study sample consisted of 1526 apparently healthy children of both genders, 1020 children were selected from schools, and 506 children were selected from children attending Maternal and Child Welfare Centers. The local ethics committee approved the current study protocol. No changes to the methods were made after trial commencement.

\section{Criteria of selection:}

1. In the case of primary teeth chronology, children from 5 months to 3 years of age were selected and their ages were determined on the basis of their date of birth. Their ages have been confirmed by their parents and their birth certificates.

2. For the chronology of permanent teeth, children from 5 to 12 years of age have been selected and their ages have been precisely determined on the basis of their birth records in the schools.

3. Apparently, the children were healthy.

4. The dentition was free from any dental abnormalities.

The purpose and procedures were explained in writing to the parents, and written consent was obtained from the parents before the examination.

\section{Sample Grouping:}

The selected children in the current study were grouped into two major categories for measuring the eruption date of primary and permanent teeth, each subdivided into two sub-groups of boys and girls.

\section{Intraoral Examination}

Children were examined using disposable mouth mirrors to pull back soft tissue, disposable dental probes, and LED headlights to obtain a good light condition. Both upper and lower jaws were examined and the eruption status of each primary and permanent tooth was recorded. If any part of the tooth was visible, regardless of the small part of the cusp tip or the incisal edge, the tooth was considered erupted and recorded on the survey sheet accordingly. If the tooth did not erupt, the corresponding space on the survey sheet would be left blank.

Parents and children were asked about missed teeth, and all reported lost teeth due to accident or extraction were considered erupted.

\section{Data collection}

Specially designed charts ${ }^{(17)}$. The primary \& permanent teeth were recorded, including name of the patients, their age, their gender, their medical, and their dental records. 


\section{Statistical Analysis}

The Minimum, maximum, means and standard deviation (SD) values were given with the data. Statistics on age have been rounded up towards the nearest month. For the estimation of tooth eruption, a Probit regression analysis was used. Each tooth was classified as (present or absent), limits of age were determined as upper limit (The age where the tooth is absent) and lower limit (The age where the tooth is present). The mean and SD have been derived from these values.

The t-test used to compare the eruption ages in boys and girls. The significance level was set at $\mathrm{P} \leq 0.05$. T-test is used to compare the mean age to the standard Values of McDonald, Avery, and Dean ${ }^{(14)}$. The correlation between chronological \& developmental age of eruption was presented as the percentage of deviation from the normal standard range of primary and permanent teeth. This Percentage was calculated by subtracting the count of cases within the normal from all the cases lying within the minimum and maximum age of eruption. IBM ${ }^{\circledR}$ SPSS ${ }^{\circledR}$ Statistics Version 20 for Windows has been used to evaluate statistics ${ }^{(18)}$.

\section{RESULTS}

\section{Primary Dentition}

\section{Mean age of eruption}

》Boys:

In both jaws, the minimum age of eruption was 0.46 year for both UA and LA, and the maximum was 2.69 year for the UE and LE. The earliest tooth to emerge in boys was the LA at mean age of 0.65 year, while the UE was the last tooth at mean age of 1.35 year, shown in Table 1 .

\section{» Girls:}

In the upper and lower jaws, the minimum age of eruption was 0.45 year for the UA and the maximum age of eruption was 2.57 years for the UE, LE, and LC. The earliest tooth to emerge in girls was LA at mean age of 0.73 year, while UE was the last tooth to erupt at mean age of 1.14 year, as shown in Table 2 .

TABLE (1) Mean, Standard Deviation (SD), Minimum and Maximum ages of eruption of primary teeth in boys.

\begin{tabular}{|c|c|c|c|c|c|}
\hline Jaw & Tooth & $\begin{array}{c}\text { Mean } \\
\text { (Year) }\end{array}$ & SD & $\begin{array}{c}\text { Min. } \\
\text { (Year) }\end{array}$ & $\begin{array}{c}\text { Max. } \\
\text { (Year) }\end{array}$ \\
\hline Upper & UA & 0.74 & 0.36 & 0.46 & 1.14 \\
\cline { 2 - 6 } & UB & 1.05 & 0.38 & 0.74 & 1.32 \\
\cline { 2 - 6 } & UC & 1.19 & 0.37 & 0.91 & 2.46 \\
\cline { 2 - 6 } & UD & 1.12 & 0.38 & 1.08 & 2.19 \\
\cline { 2 - 6 } & UE & 1.35 & 0.44 & 1.08 & 2.69 \\
\hline Lower & LA & 0.65 & 0.28 & 0.46 & 0.91 \\
\cline { 2 - 6 } & LB & 1.10 & 0.36 & 0.75 & 1.42 \\
\cline { 2 - 6 } & LC & 1.21 & 0.37 & 1.12 & 2.46 \\
\cline { 2 - 6 } & LD & 1.12 & 0.36 & 1.02 & 2.19 \\
\cline { 2 - 6 } & LE & 1.32 & 0.42 & 1.25 & 2.69 \\
\hline
\end{tabular}

SD: Standard Deviation.

Min.: Minimum ages of eruption of primary teeth in boys.

Max.: Maximum ages of eruption of primary teeth in boys.

TABLE (2) Mean, Standard Deviation (SD), Minimum and Maximum ages of eruption of primary teeth in girls.

\begin{tabular}{|c|c|c|c|c|c|}
\hline Jaw & Tooth & $\begin{array}{c}\text { Mean } \\
\text { (Year) }\end{array}$ & SD & $\begin{array}{c}\text { Min. } \\
\text { (Year) }\end{array}$ & $\begin{array}{c}\text { Max. } \\
\text { (Year) }\end{array}$ \\
\hline Upper & UA & 0.75 & 0.33 & 0.45 & 1.16 \\
\cline { 2 - 6 } & UB & 0.81 & 0.33 & 0.5 & 1.75 \\
\cline { 2 - 6 } & UC & 1.00 & 0.41 & 0.83 & 2.19 \\
\cline { 2 - 6 } & UD & 0.91 & 0.38 & 0.89 & 2.19 \\
\cline { 2 - 6 } & UE & 1.14 & 0.50 & 1.12 & 2.57 \\
\hline Lower & LA & 0.73 & 0.37 & 0.45 & 0.91 \\
\cline { 2 - 6 } & LB & 0.91 & 0.39 & 0.5 & 1.75 \\
\cline { 2 - 6 } & LC & 1.01 & 0.43 & 0.83 & 2.57 \\
\cline { 2 - 6 } & LD & 0.91 & 0.38 & 0.83 & 2.19 \\
\cline { 2 - 6 } & LE & 1.13 & 0.50 & 1.12 & 2.57 \\
\hline
\end{tabular}

SD: Standard Deviation.

Min.: Minimum ages of eruption of primary teeth in girls. Max.: Maximum ages of eruption of primary teeth in girls. 


\section{Comparison Between Boys and Girls:}

There was no statistically significant difference between mean age of eruption of upper and lower primary teeth in boys and girls for UA, LA, and LB shown in Table 3 and Figure 1.

TABLE (3) Mean, standard deviation (SD) values and comparison between ages of eruption of primary teeth in boys and girls.

\begin{tabular}{|c|c|c|c|c|c|c|}
\hline \multicolumn{2}{|c|}{ Gender } & \multicolumn{2}{|c|}{ Boys } & \multicolumn{2}{|c|}{ Girls } & \multirow[t]{2}{*}{$P$-value } \\
\hline Jaw & Tooth & $\begin{array}{l}\text { Mean } \\
\text { (Year) }\end{array}$ & SD & $\begin{array}{l}\text { Mean } \\
\text { (Year) }\end{array}$ & SD & \\
\hline \multirow{5}{*}{$\begin{array}{l}\overrightarrow{0} \\
\hat{a}\end{array}$} & UA & .74 & 0.36 & 0.75 & 0.33 & $0.564 \mathrm{NS}$ \\
\hline & UB & 1.05 & 0.38 & 0.81 & 0.33 & $0.005^{*}$ \\
\hline & $\mathrm{UC}$ & 1.19 & 0.37 & 1.00 & 0.41 & $0.008 *$ \\
\hline & UD & 1.12 & 0.38 & 0.91 & 0.38 & $0.006^{*}$ \\
\hline & UE & .35 & 0.44 & 1.14 & 0.50 & $0.001 *$ \\
\hline \multirow{5}{*}{$\begin{array}{l}0 \\
0 \\
0 \\
0\end{array}$} & LA & 0.65 & 0.28 & 0.73 & 0.37 & $0.678 \mathrm{NS}$ \\
\hline & LB & 1.10 & 0.36 & 0.91 & 0.39 & $0.453 \mathrm{NS}$ \\
\hline & LC & 1.21 & 0.37 & 1.01 & 0.43 & $0.006^{*}$ \\
\hline & LD & 1.12 & 0.36 & 0.91 & 0.38 & $0.007 *$ \\
\hline & LE & 1.32 & 0.42 & 1.13 & 0.50 & $0.001 *$ \\
\hline
\end{tabular}

SD: Standard Deviation. *: Significant at $P \leq 0.05$.

NS: Non-Significant.

\section{Sequence of Eruption of Primary Teeth}

In Boys:

The first tooth to erupt is LA followed by UA, UB, LB, UD, LD, UC, LC, LE, and finally UE (Figure 2).

In Girls:

The first tooth to erupt is LA followed by UA, $\mathrm{UB}, \mathrm{LB}, \mathrm{UD}, \mathrm{LD}, \mathrm{UC}, \mathrm{LC}, \mathrm{LE}$, and finally UE (Figure 3).

» Mean age of Eruption of Primary Teeth in Comparison with The Standard Range and Percentage of Deviation from the Standard Range: shown for Boys in Table 4, however for Girls in Table 5.

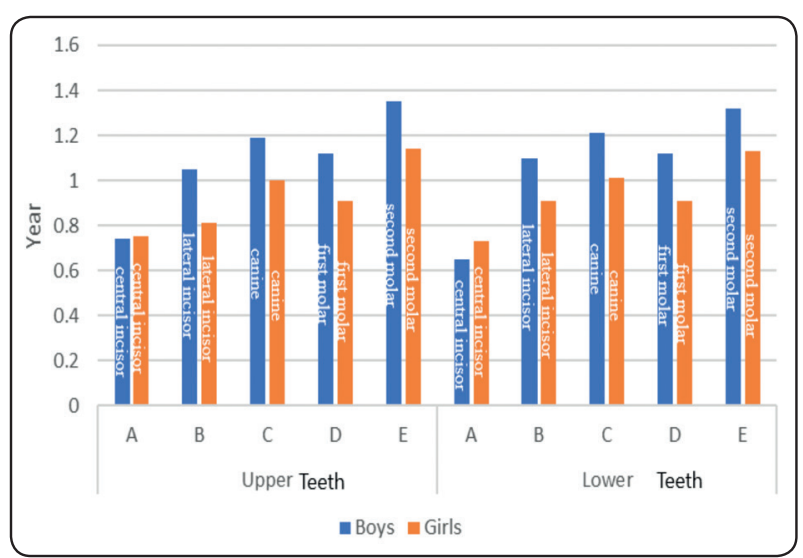

Fig. (1) Bar chart representing ages of eruption of primary teeth in boys and girls.

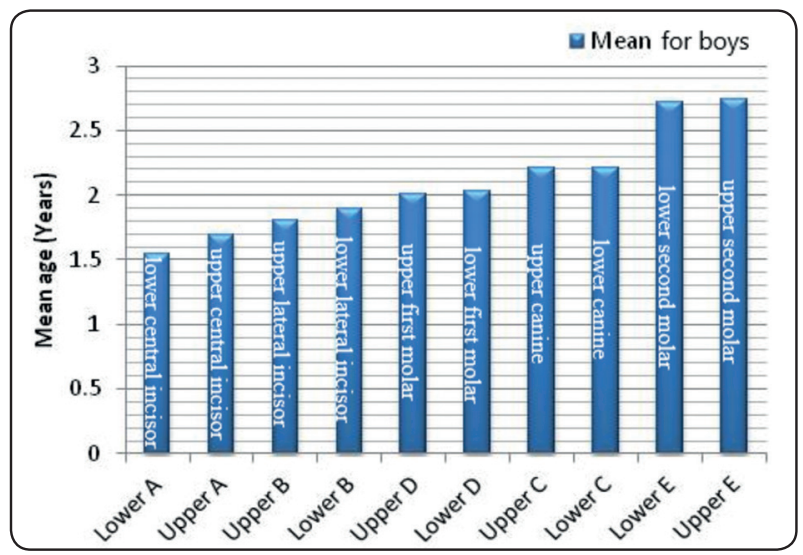

Fig. (2): Bar chart representing sequence of eruption of primary teeth in boys in ascending order.

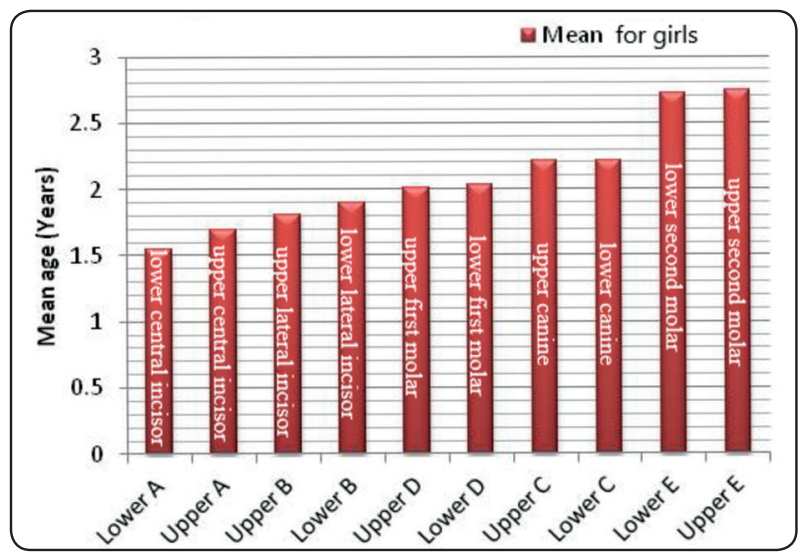

Fig. (3): Bar chart representing sequence of eruption of primary teeth in girls in ascending order. 
TABLE (4) Showing Mean, (SD), Minimum and Maximum ages of eruption of Primary teeth in boys and comparison to standard range and percentage of deviation from standard range.

\begin{tabular}{|l|l|l|l|l|l|l|}
\hline \multirow{2}{*}{ Jaw } & Tooth & Mean (year) & SD & Normal Rang & p-value & $\begin{array}{l}\text { \% of deviation from } \\
\text { normal range }\end{array}$ \\
\hline \multirow{5}{*}{ Upper } & UA & 0.74 & 0.36 & $0.83(0.67-1)$ & $0.621 \mathrm{NS}$ & $47.7 \%$ \\
\cline { 2 - 7 } & UB & 1.05 & 0.38 & $0.92(0.75-1.08)$ & $0.870 \mathrm{NS}$ & $41.1 \%$ \\
\cline { 2 - 7 } & UC & 1.19 & 0.37 & $1.58(1.33-1.83)$ & $\leq 0.001 *$ & $34.7 \%$ \\
\cline { 2 - 7 } & UD & 1.12 & 0.38 & $1.33(1.08-1.58)$ & $0.005 *$ & $34.8 \%$ \\
\cline { 2 - 7 } & UE & 1.35 & 0.44 & $2.42(2.08-2.75)$ & $\leq 0.001 *$ & $64.7 \%$ \\
\cline { 2 - 7 } & LA & 0.65 & 0.28 & $0.67(0.5-0.83)$ & $0.981 \mathrm{NS}$ & $81.0 \%$ \\
\cline { 2 - 7 } & LC & 1.10 & 0.36 & $1.08(0.83-1.33)$ & $0.671 \mathrm{NS}$ & $30.9 \%$ \\
\cline { 2 - 7 } & LD & 1.21 & 0.37 & $1.67(1.42-1.92)$ & $\leq 0.001 *$ & $37.0 \%$ \\
\cline { 2 - 6 } & LE & 1.32 & 0.36 & $1.33(1.17-1.5)$ & $0.835 \mathrm{NS}$ & $22.2 \%$ \\
\hline
\end{tabular}

SD: Standard Deviation.

*: Significant at $P \leq 0.05$.

NS: Non-Significant.

TABLE (5) Mean, standard deviation (SD), Minimum and Maximum ages of eruption of Primary teeth in Girls and comparison to standard range and percentage of deviation from standard range.

\begin{tabular}{|c|c|c|c|c|c|c|}
\hline Jaw & Tooth & Mean (year) & SD & Normal Rang & $\mathrm{p}$-value & $\begin{array}{c}\% \text { of deviation from } \\
\text { normal range }\end{array}$ \\
\hline \multirow[t]{5}{*}{ Upper } & UA & 0.75 & 0.33 & $0.83(0.67-1)$ & $0.671 \mathrm{NS}$ & $36.9 \%$ \\
\hline & UB & 0.81 & 0.33 & $0.92(0.75-1.08)$ & $0.432 \mathrm{NS}$ & $32.5 \%$ \\
\hline & UC & 1.00 & 0.41 & $1.58(1.33-1.83)$ & $\leq 0.001 *$ & $61.3 \%$ \\
\hline & UD & 0.91 & 0.38 & $1.33(1.08-1.58)$ & $\leq 0.001 *$ & $49.1 \%$ \\
\hline & UE & 1.14 & 0.50 & $2.42(2.08-2.75)$ & $\leq 0.001 *$ & $50.0 \%$ \\
\hline \multirow[t]{5}{*}{ Lower } & LA & 0.73 & 0.37 & $0.67(0.5-0.83)$ & $0.123 \mathrm{NS}$ & $60.6 \%$ \\
\hline & LB & 0.91 & 0.39 & $1.08(0.83-1.33)$ & $0.004 *$ & $72.3 \%$ \\
\hline & LC & 1.01 & 0.43 & $1.67(1.42-1.92)$ & $\leq 0.001 *$ & $55.8 \%$ \\
\hline & LD & 0.91 & 0.38 & $1.33(1.17-1.5)$ & $\leq 0.001 *$ & $53.8 \%$ \\
\hline & LE & 1.13 & 0.50 & $2.25(1.92-2.58)$ & $\leq 0.001 *$ & $69.2 \%$ \\
\hline
\end{tabular}

SD: Standard Deviation. *: Significant at P $\leq 0.05$. NS: Non-Significant. 


\section{Permanent Dentition}

\section{Mean age of eruption}

» Boys:

In the upper jaw, the minimum age of eruption was 5.86 years for the $\mathrm{U} 1$ and $\mathrm{U} 2$, and the maximum was 13.18 years for the U3, U7, and L7, while in the lower jaw, the minimum age was 5.21 years for the L1 and L6, and the maximum was 13.18 years for L7 (Table 6).

" Girls:

In the upper jaw, the minimum age of eruption was 5.0 years for U6 and the maximum age was 12.35 years for $\mathrm{U} 3$, while in the lower jaw, the minimum age was 5.0 years for the permanent L1 and L6, and the maximum age was 12.20 years for L5 (Table 7).

\section{Comparison between Boys and Girls:}

There was no statistically significant difference in U3, L3, U4, L4, U7, L7, L1, L2, and L5 (Table 8) and (Figure 4).

\section{Sequence of Eruption of Permanent Teeth:}

\section{In Boys:}

The first tooth to erupt is L6 followed by L1, L2, $\mathrm{U} 1, \mathrm{U} 2, \mathrm{U} 6, \mathrm{~L} 4, \mathrm{U} 4, \mathrm{U} 5, \mathrm{~L} 3, \mathrm{~L} 5, \mathrm{~L} 7, \mathrm{U} 7$, and at last U3 (Figure 5).

In Girls:

The first tooth to erupt is L1 followed by L2, U1, U2, U6, L6, L3, L4, L5, U4, U5, L7, U7, and at last U3 (Figure 6).

» Mean age of eruption of Permanent Teeth in comparison to The Standard Range and Percentage of Deviation from Standard Range: shown for Boys in Table 9, however for Girls in Table 10.

TABLE (6) Mean, Standard Deviation (SD), Minimum and Maximum ages of eruption of permanent teeth in boys.

\begin{tabular}{|c|c|c|c|c|c|}
\hline \multirow{3}{*}{ Jaw } & Tooth & Mean (year) & SD & $\begin{array}{c}\text { Minimum age of eruption } \\
\text { (year) }\end{array}$ & $\begin{array}{c}\text { Maximum age of eruption } \\
\text { (year) }\end{array}$ \\
\hline \multirow{5}{*}{} & U1 & 7.94 & 0.74 & 5.86 & 9.09 \\
\cline { 2 - 6 } & U2 & 9.47 & 1.18 & 5.86 & 11.12 \\
\cline { 2 - 6 } & U3 & 11.73 & 0.79 & 9.14 & 13.18 \\
\cline { 2 - 6 } & U4 & 10.55 & 0.62 & 9.09 & 11.51 \\
\cline { 2 - 6 } & U5 & 10.72 & 0.67 & 8.74 & 11.58 \\
\cline { 2 - 6 } & U6 & 10.00 & 0.70 & 8.74 & 11.12 \\
\hline \multirow{4}{*yyyy}{} & L1 & 11.71 & 0.67 & 10.47 & 9.87 \\
\cline { 2 - 6 } & L2 & 7.84 & 1.14 & 5.21 & 9.09 \\
\cline { 2 - 6 } & L3 & 10.81 & 0.84 & 5.86 & 11.73 \\
\cline { 2 - 6 } & L4 & 10.07 & 1.06 & 8.67 & 11.30 \\
\cline { 2 - 6 } & L5 & 10.99 & 0.94 & 7.67 & 11.84 \\
\cline { 2 - 6 } & L6 & 7.38 & 0.98 & 7.28 & 9.14 \\
\hline
\end{tabular}

SD: Standard Deviation. 
TABLE (7) Mean, Standard Deviation (SD), Minimum and Maximum ages of eruption of permanent teeth in girls.

\begin{tabular}{|c|c|c|c|c|c|}
\hline \multirow{3}{*}{ Jaw } & Tooth & Mean (year) & SD & $\begin{array}{c}\text { Minimum age of erup- } \\
\text { tion (year) }\end{array}$ & $\begin{array}{c}\text { Maximum age of } \\
\text { eruption (year) }\end{array}$ \\
\hline \multirow{5}{*}{ Upper } & U1 & 8.15 & 0.96 & 5.42 & 9.96 \\
\cline { 2 - 6 } & U2 & 8.41 & 0.90 & 7.09 & 9.96 \\
\cline { 2 - 6 } & U3 & 11.14 & 0.86 & 8.64 & 12.35 \\
\cline { 2 - 6 } & U4 & 10.94 & 0.99 & 7.62 & 12.24 \\
\cline { 2 - 6 } & U5 & 11.02 & 0.89 & 8.64 & 12.24 \\
\hline \multirow{7}{*}{ Lower } & U6 & 8.72 & 1.71 & 5.00 & 11.51 \\
\cline { 2 - 6 } & U7 & 7.18 & 0.80 & 7.16 & 7.24 \\
\cline { 2 - 6 } & L2 & 10.62 & 1.20 & 5.00 & 7.94 \\
\cline { 2 - 6 } & L3 & 10.77 & 1.15 & 5.41 & 12.08 \\
\cline { 2 - 6 } & L4 & 10.86 & 1.09 & 7.39 & 12.18 \\
\cline { 2 - 6 } & L5 & 8.97 & 1.88 & 7.39 & 12.20 \\
\hline
\end{tabular}

SD: Standard Deviation.

TABLE (8) Mean, standard deviation (SD) values and comparison between ages of eruption of permanent teeth in boys and girls.

\begin{tabular}{|c|c|c|c|c|c|c|}
\hline \multicolumn{2}{|c|}{ Gender } & \multicolumn{2}{|c|}{ Boys } & \multicolumn{2}{|c|}{ Girls } & \multirow{2}{*}{$P$-value } \\
\hline Jaw & Tooth & Mean(year) & SD & Mean(year) & $\mathrm{SD}$ & \\
\hline \multirow{7}{*}{ Upper } & U1 & 7.94 & 0.74 & 8.15 & 0.96 & $0.0001 *$ \\
\hline & $\mathrm{U} 2$ & 9.47 & 1.18 & 8.41 & 0.90 & $0.0001 *$ \\
\hline & U3 & 11.73 & 0.79 & 11.14 & 0.86 & $0.23 \mathrm{NS}$ \\
\hline & U4 & 10.55 & 0.62 & 10.94 & 0.99 & $0.21 \mathrm{NS}$ \\
\hline & U5 & 10.72 & 0.67 & 11.02 & 0.89 & $0.0001 *$ \\
\hline & U6 & 10.00 & 0.70 & 8.72 & 1.71 & $0.0001 *$ \\
\hline & U7 & 11.71 & 0.67 & 11.13 & 1.02 & $0.8 \mathrm{NS}$ \\
\hline \multirow{7}{*}{ Lower } & $\mathrm{L} 1$ & 7.84 & 1.14 & 7.18 & 0.80 & $0.653 \mathrm{NS}$ \\
\hline & $\mathrm{L} 2$ & 7.93 & 0.82 & 7.25 & 0.71 & $0.56 \mathrm{NS}$ \\
\hline & L3 & 10.81 & 0.84 & 10.62 & 1.20 & $0.625 \mathrm{NS}$ \\
\hline & $\mathrm{L} 4$ & 10.07 & 1.06 & 10.77 & 1.15 & $0.453 \mathrm{NS}$ \\
\hline & L5 & 10.99 & 0.94 & 10.86 & 1.09 & $0.989 \mathrm{NS}$ \\
\hline & L6 & 7.38 & 0.98 & 8.97 & 1.88 & $0.0001 *$ \\
\hline & L7 & 11.59 & 0.84 & 11.10 & 0.77 & $0.546 \mathrm{NS}$ \\
\hline
\end{tabular}

SD: Standard Deviation. $\quad$ *: Significant at $P \leq 0.05 . \quad$ NS: Non-Significant 
TABLE (9) Mean, standard deviation (SD), Minimum and Maximum ages of eruption of Permanent teeth and comparison to standard range and percentage of deviation from standard range Male.

\begin{tabular}{|c|c|c|c|c|c|c|}
\hline Jaw & Tooth & $\begin{array}{l}\text { Mean } \\
\text { (year) }\end{array}$ & $\pm \mathrm{SD}$ & $\begin{array}{l}\text { Standard } \\
\text { range }\end{array}$ & p-value & $\begin{array}{c}\% \text { of deviation from normal } \\
\text { range }\end{array}$ \\
\hline \multirow{7}{*}{ Upper } & U1 & 7.94 & 0.74 & $7.5(7-8)$ & $0.003 *$ & $38.5 \%$ \\
\hline & $\mathrm{U} 2$ & 9.47 & 1.18 & $8.5(8-9)$ & $0.005^{*}$ & $46.4 \%$ \\
\hline & U3 & 11.73 & 0.79 & $11.5(11-12)$ & $0.671 \mathrm{NS}$ & $5.4 \%$ \\
\hline & U4 & 10.55 & 0.62 & $10.5(10-11)$ & $\leq 0.001^{*}$ & $65.7 \%$ \\
\hline & U5 & 10.72 & 0.67 & $11(10-12)$ & $\leq 0.001 *$ & $58.6 \%$ \\
\hline & U6 & 10.00 & 0.70 & $6.5(6-7)$ & $\leq 0.001 *$ & $53.6 \%$ \\
\hline & U7 & 11.71 & 0.67 & $12.5(12-13)$ & $0.571 \mathrm{NS}$ & $46.2 \%$ \\
\hline \multirow{7}{*}{ Lower } & L1 & 7.84 & 1.14 & $6.5(6-7)$ & $0.324 \mathrm{NS}$ & $35.6 \%$ \\
\hline & $\mathrm{L} 2$ & 7.93 & 0.82 & $7.5(7-8)$ & $0.835 \mathrm{NS}$ & $11.6 \%$ \\
\hline & L3 & 10.81 & 0.84 & $9.5(9-10)$ & $\leq 0.001^{*}$ & $74.2 \%$ \\
\hline & L4 & 10.07 & 1.06 & $11(10-12)$ & $\leq 0.001^{*}$ & $58.1 \%$ \\
\hline & L5 & 10.99 & 0.94 & $11.5(11-12)$ & $\leq 0.001^{*}$ & $51.6 \%$ \\
\hline & L6 & 7.38 & 0.98 & $6.5(6-7)$ & $\leq 0.001^{*}$ & $28.2 \%$ \\
\hline & L7 & 11.59 & 0.84 & $12(11-13)$ & $\leq 0.001 *$ & $68.2 \%$ \\
\hline
\end{tabular}

SD: Standard Deviation. *: Significant at $P \leq 0.05$.

NS: Non-Significant.

TABLE (10) Mean, standard deviation (SD), Minimum and Maximum ages of eruption of Permanent teeth and comparison to standard range and percentage of deviation from standard range Female.

\begin{tabular}{|c|c|c|c|c|c|c|}
\hline Jaw & Tooth & Mean (year) & $\pm \mathrm{SD}$ & Standardrange & p-value & $\%$ of deviation from normal range \\
\hline \multirow{7}{*}{ Upper } & U1 & 8.15 & 0.96 & $7.5(7-8)$ & $\leq 0.001 *$ & $38.4 \%$ \\
\hline & $\mathrm{U} 2$ & 8.41 & 0.90 & $8.5(8-9)$ & $0.870 \mathrm{NS}$ & $22.7 \%$ \\
\hline & $\mathrm{U} 3$ & 11.14 & 0.86 & $11.5(11-12)$ & $\leq 0.001 *$ & $22.6 \%$ \\
\hline & U4 & 10.94 & 0.99 & $10.5(10-11)$ & $0.990 \mathrm{NS}$ & $10.1 \%$ \\
\hline & U5 & 11.02 & 0.89 & $11(10-12)$ & $\leq 0.001 *$ & $77.4 \%$ \\
\hline & U6 & 8.72 & 1.71 & $6.5(6-7)$ & $\leq 0.001 *$ & $55.8 \%$ \\
\hline & U7 & 11.13 & 1.02 & $12.5(12-13)$ & $\leq 0.001 *$ & $53.1 \%$ \\
\hline \multirow{7}{*}{ Lower } & L1 & 7.18 & 0.80 & $6.5(6-7)$ & $\leq 0.001 *$ & $37.0 \%$ \\
\hline & L2 & 7.25 & 0.71 & $7.5(7-8)$ & $0.564 \mathrm{NS}$ & $18.9 \%$ \\
\hline & L3 & 10.62 & 1.20 & $9.5(9-10)$ & $\leq 0.001 *$ & $46.7 \%$ \\
\hline & L4 & 10.77 & 1.15 & $11(10-12)$ & $\leq 0.001 *$ & $42.4 \%$ \\
\hline & L5 & 10.86 & 1.09 & $11.5(11-12)$ & $\leq 0.001 *$ & $53.1 \%$ \\
\hline & L6 & 8.97 & 1.88 & $6.5(6-7)$ & $\leq 0.001 *$ & $24.5 \%$ \\
\hline & L7 & 11.10 & 0.77 & $12(11-13)$ & $\leq 0.001 *$ & $47.6 \%$ \\
\hline
\end{tabular}




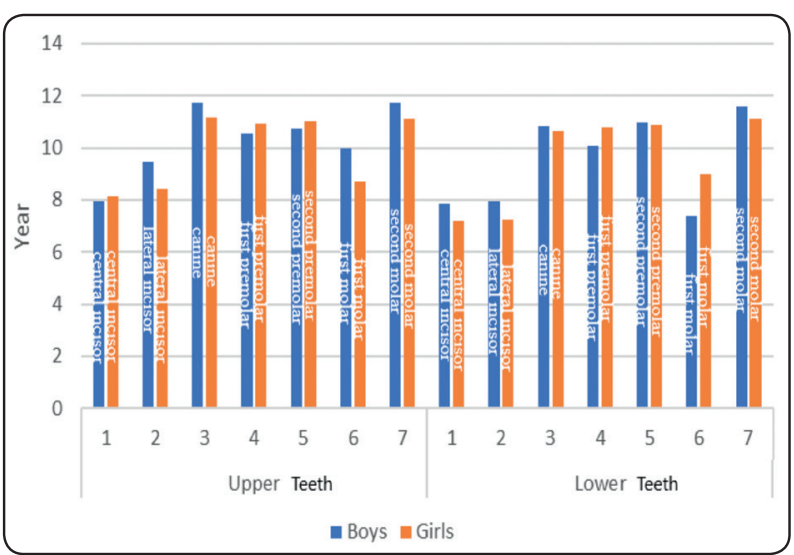

Fig. (4): Bar chart representing ages of eruption of permanent teeth in boys and girls.

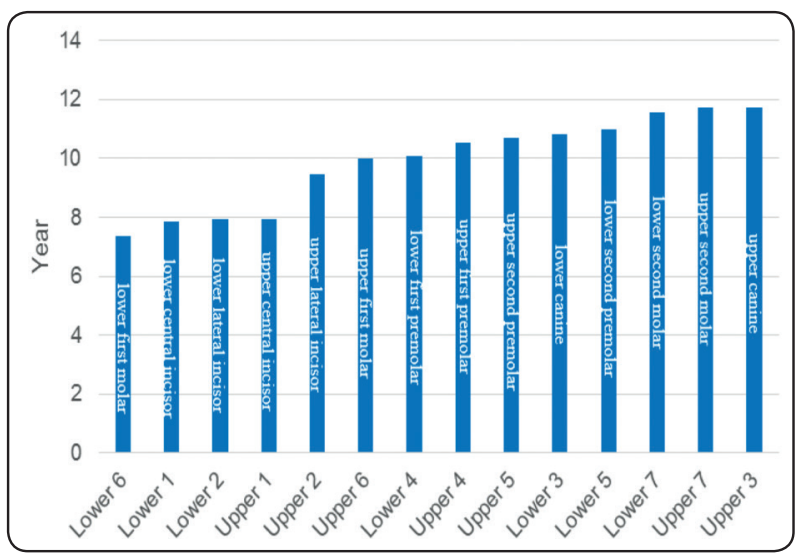

Fig. (5) shows the sequence of eruption of permanent teeth in boys.

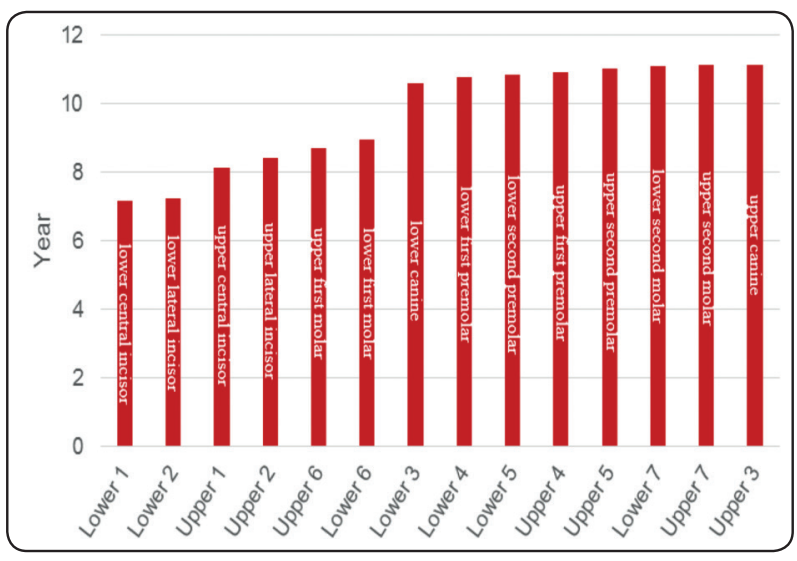

Fig. (6): the sequence of eruption of permanent teeth in girls.

\section{DISCUSSION}

Limited numbers of studies were published from Middle Eastern countries on the eruption age of teeth. Therefore, information utilized is still based on American and European standards ${ }^{(19)}$.

To determine an accurate mean age of eruption of each tooth and the most common sequence of eruption, the authors have to access a large number of children whose exact ages are known ${ }^{(20)}$.

So, the selected sample size of the present study represents an average size to be considered quantitatively (large number of patients), and qualitatively (because it was composed of patients with average living standards) in relation to previous studies which selected the same sample size.

The children selected from Maternal and Child Welfare Center-aged from 5 months to 3 years old, this age was selected to include the beginning of emergence of first primary tooth till the eruption of last primary tooth. This comes in agreement with other studies in India ${ }^{(11)}$ and in Egypt ${ }^{(12,13,15,21,22)}$.

The children selected from different Primary schools aged from 5-12 years old; this age was selected to include the beginning of emergence of first permanent tooth till the eruption of last permanent tooth. This comes in agreement with other studies in $\operatorname{Egypt}^{(12,13,15,16,23,24)}$.

During the oral examination, if any part of the primary or permanent tooth was visible or had penetrated the gingiva, the tooth was considered "erupted", because the actual eruption of the tooth occurs when it breaks through the gum ${ }^{(25)}$.

One of the challenges faced during the performance of the present study, was early extraction of teeth in some children, so it was difficult to differentiate between delayed eruption and premature extraction without X-Ray, or early eruption may be due to the extraction of the deciduous teeth with periapical infection and bone resorption. 
In boys, the first primary tooth erupted was LA, at a mean age of 0.65 year, close to previous studies conducted in Egypt ${ }^{(22)}$ who reported that the mean age was 0.66 year, and it was earlier than other studies ${ }^{(12,15,26)}$ who reported that the mean ages were $0.86,1.56$ and 0.75 year respectively, and in relation to other populations, it was far early than Indian study ${ }^{(11)}$, who concluded that the mean age was 1.083 year, and close to Jordanian study ${ }^{(27)}$ who was at a mean age of 0.69 year.

In girls, the first primary tooth erupted was also the LA but at the mean age of 0.73 year, which was earlier than other studies ${ }^{(15,26)}$ who reported that the mean ages were 0.92 and 0.9 year respectively, and it was delayed than other studies ${ }^{(22,27)}$ who reported that the mean ages were 0.65 and 0.67 year respectively, and it was far earlier than a study from Egypt ${ }^{(12)}$ who reported that the mean age was 1.58 year.

Except for UA and LA, all primary teeth erupted earlier in girls than in boys, which close to previous Jordanian study ${ }^{(27)}$ and disagreed with other studies from Egypt ${ }^{(12,13,22,26)}$ and with many other studies on different populations like Saudi Arabians ${ }^{(28)}$, Nigerians (29) and Australians ${ }^{(30)}$. Such earlier eruption may be explained to be a sign of earlier maturation of girls when compared to boys.

Consistent with the findings reported from different populations like Nepal ${ }^{(31)}$, Australia ${ }^{(30)}$, and Jordan ${ }^{(27)}$ and the findings reported from Egyptian children ${ }^{(12,15,22,26)}$. The results of the present study indicated that the sequence of primary teeth eruption was according to the following order: central incisor, lateral incisor, first molar, canine and second molar. This sequence followed the standard values ${ }^{(14)}$.

In general, it was found in the present study that the maxillary primary teeth showed earlier eruption dates in relation to their mandibular primary counterparts for both genders, except for UA and UE for both genders, this general maxillary precedence was consistent with the previous studies for both genders ${ }^{(12,26,30)}$ and another study ${ }^{(32)}$ for boys only.
This could be explained by earlier development and mineralization of tooth buds of maxillary teeth that preceded the tooth buds of mandibular teeth.

When both arches were combined, the sequence of eruption was similar to Indian study ${ }^{(33)}$ and another study from Egypt ${ }^{(15)}$, as the UA and UB erupted earlier than LB for both genders, contradicting the general agreement that lateral incisors erupted first in the maxilla, and that agreed with other Egyptian studies ${ }^{(12,26)}$.

In the present study, it was found that there is no difference in the sequence of eruption of primary teeth in boys and girls, and that reported in other studies ${ }^{(12,26,30)}$. This is maybe explained by the similarity of growth patterns between boys and girls in childhood.

As regarding boys group, the first permanent tooth erupted was the L6 at a mean age of 7.38 years, which was consistent with study in KafrElsheikh governorate ${ }^{(12)}$ and in other populations like Indians ${ }^{(34)}$ and Jordanians ${ }^{(23)}$. But in Giza governorate $^{(15)}$ and other Egyptian study ${ }^{(16)}$ and a study from Lithuanians ${ }^{(24)}$, it was found that the first permanent tooth erupted in boys was the L1 at a mean age around 6 years.

As regarding girls group, the first permanent tooth erupted was the L1 at a mean age of 7.84 years which was consistent with the previous study by Spanish ${ }^{(35)}$ and Egyptians ${ }^{(16)}$ and with Lithuanians ${ }^{(24)}$. However it was inconsistent with study in KafrElsheikh governorate ${ }^{(12)}$ who reported that the U6 was the first tooth to erupt, also it was not consistent with Malaysians ${ }^{(36)}$, Jordanians ${ }^{(23)}$ and Egyptians in Giza ${ }^{(15)}$, which reported that the L6 erupted first at a mean age of 6.4,6.08 and 6.5 years respectively.

Except for U1, U5, L6, U4 and L4, all permanent teeth erupted earlier in girls than in boys, which close to previous Egyptian studies ${ }^{(12,16)}$ and with many other studies on different populations, like Australians (37), Saudi ${ }^{(28)}$, Turkish ${ }^{(38)}$, India ${ }^{(33)}$, Lithuanians (24) and Jordanians (23) and disagreed with Egyptian study in Giza ${ }^{(15)}$. This earlier eruption 
can be explained to be a sign of earlier maturation of girls when compared to boys.

The sequence of eruption of canines and premolars in the maxilla were U4, U5 then U3 for both genders which was similar to other studies ${ }^{(15,16)}$ and a study in Kafr-Elsheikh for boys ${ }^{(12)}$. While in the mandible, the sequence was L4, L3 then L5 for boys which was also similar to Egyptian studies ${ }^{(15,16)}$ but it was not similar in girls as the sequence was L3, L4 then L5 which was similar to a study in KafrElsheikh ${ }^{(12)}$ and in other population like Malaysians (36) and Romanians ${ }^{(35)}$, that may be due to the difference in geographic location, nutrition and environmental factors, which may cause the difference.

There was high percentage of deviation from the standard range exceeding $45 \%$ for most of the permanent teeth in both boys and girls. This can be explained by high caries prevalence for primary teeth in Asia and Africa ${ }^{(39)}$ resulting in premature loss of primary teeth. Eruption of the premolar teeth could be delayed in children who lose primary molars at 4 or 5 years of age and before. If primary molars are extracted after the age of 5 years, delayed premolar eruptions have decreased. At 8, 9, and 10 years of age, premolar eruption resulting from premature loss of primary teeth was greatly accelerated ${ }^{(14)}$.

Finally, the present study provided some relevant information about the mean times of eruption and the most common sequence of eruption of primary and permanent teeth among group of children. These findings may be helpful for pedodontists, orthodontists, academicians, and individuals who work in field of health education. Also, it is important to consider that tooth eruption is affected by different factors (environmental, nutritional, and genetics).

\section{CONCLUSIONS}

- Maxillary primary teeth showed earlier eruption dates in relation to their mandibular counterparts for both genders, except for UA and UE for both genders.
- Mandibular permanent teeth in both genders erupted before their maxillary opponents except for U5 in boys and U6 in girls.

- Girls preceded boys in primary teeth eruption except for the UA and LA.

- All permanent teeth erupted earlier in girls than in boys except for U1 and U5, L6, U4, and L4.

- The permanent dentition exhibited little more deviation from the standard range (14) than in the primary dentition.

- Specific standards of Eruption dates \& sequence should be the basis for diagnosis, treatment planning, and preventive programs upon which orthodontists and pediatric dentists can rely on.

- Chronological age and developmental age are usually not the same as certain children demonstrate that major individual factors play a role in the eruption of the teeth as hereditary factors and dietary status of children.

\section{Funding:}

No specific funding from funders in the public, commercial, or non-profit sectors has been given to this study.

\section{Conflicts of interest:}

There is no conflict of interest for any of the authors.

\section{REFERENCES}

1. Park, J.H., Tai, K. and Iida, S. (2013) Unilateral delayed eruption of a mandibular permanent canine and the maxillary first and second molars, and agenesis of the maxillary third molar. Am. J. Orthod. Dentofac. Orthop., 143, 134-139.

2. Suri, L., Gagari, E. and Vastardis, H. (2004) Delayed tooth eruption: Pathogenesis, diagnosis, and treatment. A literature review. Am. J. Orthod. Dentofac. Orthop., 126, $432-445$.

3. 3. Pacurar,M.,Bica, C. and Martha, K. (2016) Examination Of Teeth Eruption In The Support Area Of The Romanian 
Subjects Irinel Panainte (Postgraduate Student, DMD). Eur. Sci. J., 12, 395-402.

4. Ragghianti-Zangrando, M.S., Veronesi, G.F., Cardoso, M.V., et al. (2017) Altered Active and Passive Eruption: A Modified Classification. Clin. Adv. Periodontics, 7, 51-56.

5. Mars, J. and Palti, A. (2011) of Oral Rehabilitation. Rom. J. Oral Rehabil., 3, 30-31.

6. Chu, C.H. and Yeung, C. (2014) A review of the eruption of primary teeth. OA Dent., 39, 1-24.

7. Baral, P., Banstola, D. and Shrestha, R. (2014) A Study of Relationship Between Body Mass Index (BMI) and Emergence of Permanent Teeth in Children of Aryan and Mongoloid Races. J. Gandaki. Med. Coll., 7, 19-22.

8. Almonaitiene, R., Balciuniene, I., Tutkuviene, J., et al. (2010) Factors Influencing Permanent Teeth Eruption. Bal. Dent. Maxillofac. J., 12, 67-72.

9. Khalifa,A.M.,Atef, R., Gendy, E., et al. (2014) Relationship between gestational age, birth weight and deciduous tooth eruption. Egypt. Pediatr. Assoc. Gaz., 62, 41-45.

10. Peedikayil, F.C. (2011) Delayed tooth eruption. E-Journal Dent., 1, 81-86.

11. Rao, A., Shenoy, R., et al. (2014) Changing trends in tooth eruption-survey among children of Mangalore, India. Int. J. Adv. Res., 2, 449-454.

12. Abd El-Hakam, R.M., Taha, S.E., Abou El Yazeed, M., et al. (2015) the Eruption Sequence of Primary and Permanent Teeth in a Group of Children in Kafr-Elsheikh Governorate, Egypt. Review Of Research, 4, 1-11.

13. Darwish, Y., Taha, S., Abou El Yazeed, M., et al. (2016) Eruption sequence of children primary and permanent teeth in an urban area of El Qualubia Governorate. Indian Streams Res. J., 6, 1-16.

14. McDonald, R.E., Avery, D.R. and Dean, J.A. (2011) Eruption of the Teeth: Local, Systemic, and Congenital Factors That Influence the Process. McDonald and Avery Dentistry for the Child and Adolescent. Elsevier Inc., 150-176.

15. Helmy, R., Taha, S.and Abou El Yazeed, M. (2016) Eruption Sequence Of Primary and Permanent Teeth in a Group of Egyptian Children at Giza Governorate. Indian Streams Res. J., 6, 1-15.

16. Sharaf, R., Taha, S. and El Dokky, N. (2012) A study for the eruption sequence of permanent teeth in a group of Egyptian children. Cairo Dent. J., 28, 235-239.
17. Taha, S. and El Dokky, N. (2011) Design of Diagnostic Chart to Determine the Eruption of Primary and Permanent Teeth in the Examined Egyptian Child.

18. Abdelrahman, A. (2018) IBM SPSS Statistics for Windows.

19. Khan, N., Chohan, A.N., Al-Nasser, F., et al. (2008) Statistical presentation of eruption age of permanent second molars, premolars and canines in female school children living in Riyadh, Saudi Arabia. Saudi Dent. J., 20, 140-149.

20. Leroy, R., Cecere, S., Lesaffre, E., et al. (2008) Variability in permanent tooth emergence sequences in Flemish children. Eur. J. Oral Sci.,116, 11-17.

21. El-Batran, M., Abou-Zeid, A.W. and Soliman, N.L. (2002) Dates of emergence of deciduous teeth in a sample of Egyptian children. Egypt. Dent. J., 48, 33-40.

22. Soliman, N.L., El-Zainy, M.A., Hassan, R.M., et al. (2011) Timing of deciduous teeth emergence in Egyptian children. East. Mediterr. Heal. J., 17, 875-881.

23. Shaweesh, A.I. (2012) Timing and sequence of emergence of permanent teeth in the Jordanian population. Arch. Oral. Biol., 57, 122-130.

24. Almonaitiene, R.and Tutkuviene, J. (2012) Standards for permanent teeth emergence time and sequence in Lithuanian children, residents of Vilnius city. Stomatologija, Bal. Dent. Maxillofac. J., 14, 93-100.

25. Denloye, O. (2008) Eruption sequence of first permanent teeth in some Nigerian children. Pediatr. Dent. J., 18, 1-4.

26. El-Beheri, S. and Hussein, M.H. (1987) Sequence and age of emergence for deciduous teeth among a group of children in urban and rural areas of Egypt. Egypt Dent. J., $33,13-30$.

27. Al-Batayneh, O.B., Shaweesh, A.I. and Alsoreeky, E.S. (2014) Timing and sequence of emergence of deciduous teeth in Jordanian children. Arch. Oral. Biol., 60, 126-133.

28. Al-Jasser, N. and Bello, L. (2003) Time of Eruption of Primary Dentition in Saudi Children. J. Contemp. Dent. Pract., 4, 1-7.

29. Folayan, M., Owotade, F., Adejuyigbe, E., et al. (2008) Eruption Chronology of Primary Teeth in Nigerian Children The Timing of Eruption of the Primary Dentition in Nigerian Children. J. Clin. Pediatr. Dent., 134, 443-448.

30. Woodroffe, S., Mihailidis, S., Hughes, T., et al. (2010) Primary tooth emergence in Australian children : timing, sequence and patterns of asymmetry. Aust. Dent. J., 55, 245-251. 
31. Gupta, A., Hiremath, S.S., Singh, S.K., Poudyal, S., Niraula, S.R. and Baral, D.D., Singh, R.K. (2007) Emergence of Primary Teeth in Children of Sunsari District of Eastern Nepal. McGill J. Med., 10, 11-15

32. Oziegbe, E.O., Adekoya-Sofowora, C., Esan, T.A., et al. (2008) Eruption chronology of primary teeth in Nigerian children. J. Clin. Pediatr. Dent., 32, 341-345.

33. Gunashekhar, M. and Tenny, J. (2010) Longitudinal study of age and order of eruption of primary teeth in Indian children. Community Prev. Dent. Publ., 2, 3-6.

34. Kaur, I., Singal, P., Bhatnagar, D.P., et al. (2010) Timing of Permanent Teeth Emergence and Dental Caries among Jatsikh Children of Public and Government Schools of Patiala District Dental Caries among Jatsikh Children of Public. Anthropol. ISSN, 12, 141-148.

35. Feraru,I.V., Rãducanu,A.M.,Feraru, S.E., et al. (2011) The Sequence and Chronology of the Eruption of Permanent
Canines and Premolars in a Group of Romanian Children in Bucharest. Oral Health Dent. Manag., 10, 193-198.

36. Hussin, A.S., Mokhtar, N., Naing, L., et al. (2007) The timing and sequence of emergence of permanent teeth in Malay schoolchildren in Kota Bharu, Malaysia. Arch. Orofac. Sci., 2, 36-40.

37. Sarrafpour, B., Rungsiyakull, C., Swain, M., et al. (2012) Finite element analysis suggests functional bone strain accounts for continuous post-eruptive emergence of teeth. Arch. Orofac. Sci., 57, 1070-1078.

38. Wedl, J.S., Schoder, V., Blake, F.A.S., et al. (2004) Eruption times of permanent teeth in teenage boys and girls in Izmir (Turkey). J. Clin. Forensic. Med., 11, 299-302.

39. Puska, A., Porter, D. and Petersen, P. (2003) Dental Diseases and Oral Health. World Heal. Organ. Glob. Strateg. DIET, Physical Activity And Health $@$, 2. 